Palavras chave:

Desenvolvimento Composição mineral

Produção de mudas

Solução nutritiva

Mogno africano

Histórico:

Recebido 20/10/2015

Aceito 15/03/2016

Keywords:

Growth

Mineral composition

Seedling production

Nutrient solution

African mahogany

Correspondência: graciellacor@gmail.com
Graciella Corcioli'; Jácomo Divino Borges' e Roberta Paula de Jesus'

\section{DEFICIÊNCIA DE MACRO E MICRONUTRIENTES EM MUDAS MADURAS DE KHAYA IVORENSIS ESTUDADAS EM VIVEIRO}

RESUMO: O mogno africano (Khaya ivorensis) é uma essência florestal de alto valor e de grande potencial para substituir o mogno brasileiro (Swietenia macrophylla). Atualmente, pouco se conhece a respeito das exigências nutricionais do mogno africano. Nesse sentido, o presente trabalho teve o objetivo de avaliar o desenvolvimento e a composição mineral de plantas de $K$. ivorensis submetidas à omissão de macro e micronutrientes. Para isso, realizou-se experimento com solução nutritiva, com os tratamentos: TI-Solução completa; T2-omissão de nitrogênio; T3-omissão de fósforo; T4-omissão de potássio; T5omissão de cálcio; T6-omissão de magnésio; T7-omissão de enxofre; T8-omissão de ferro; T9-omissão de boro; TI0-omissão de cobre; TII-com omissão de manganês; TI2-com omissão de zinco; TI3-com omissão de molibdênio e TI4-água deionizada. As avaliações foram realizadas a partir de mudas comerciais prontas para o plantio, que permaneceram em casa de vegetação sendo irrigadas apenas com água deionizada. Após quinze dias as plantas passaram a receber diariamente $200 \mathrm{ml}$ de solução nutritiva. O delineamento experimental utilizado foi inteiramente casualizado com quatorze tratamentos e dez repetições. Os dados dendrológicos foram descritos a cada quinze dias até tornaremse bem definidos. As plantas tiveram desenvolvimento afetado apenas pela omissão de $\mathrm{N}$, exibindo menores teores foliares do elemento. As omissões dos demais nutrientes afetaram levemente o desenvolvimento das plantas.

\section{MACRO AND MICRONUTRIENT DEFICIENCY IN MATURE SEEDLINGS OF KHAYA IVORENSIS STUDIED IN NURSERY}

ABSTRACT: African mahogany (Khaya ivorensis) is a high value forest species and of great potential to replace the brazilian mahogany (Swietenia macrophylla). Currently, little is known about the nutritional requirements of African mahogany. In this sense, the present study aimed to evaluate the growth and mineral composition $K$. ivorensis plants submitted to the omission of macro and micronutrients. For this, we carried out a experiment with nutrient solution with the following treatments: TI-Complete Solution; T2-omission of nitrogen; T3-omission of phosphorus; T4-omission of potassium; T5-omission of calcium; T6-omission of magnesium; T7-omission of sulfur; T8-omission of iron; T9-omission of boron; TI0-omission of copper; TII-omission of manganese; TI2-omission of zinc; TI3-omission of molybdenum; and TI4-deionized water. The evaluations were carried out based on commercial seedlings ready for planting, which remained in a greenhouse, irrigated only with deionized water. After fifteen days, the plants started to receive $200 \mathrm{ml}$ of nutrient solution daily. The experimental design used was completely randomized with fourteen treatments and ten replications. The dendrological data were collected every fifteen days until they became well defined. The plants had their growth affected only by the omission of $\mathrm{N}$, showing smaller contents of the element in the leaves. The omissions of the other nutrients only slightly affected the growth of plants. 


\section{INTRODUÇÃO}

A crescente escassez de madeiras nativas e sua conseqüente valorização, além da atual conscientização da população quanto à preservação do meio ambiente, conforme Perez e Bacha (2007), estimularam o desenvolvimento de tecnologias que viabilizassem o uso de outras espécies, principalmente, aquelas oriundas de reflorestamento.

O mogno brasileiro (Swietenia macrophylla) é uma das espécies de maior valor comercial do mundo, devido à beleza e qualidade da madeira e, por isso, vem sendo explorada intensivamente nas últimas décadas (GROGAN et al., 2002). No Brasil, assim como nos demais países da América Tropical, as tentativas de se cultivar mogno brasileiro para fins comerciais têm dado resultados negativos, devido à sua alta suscetibilidade ao ataque e danos provocados por Hypsipyla grandella (Zeller). Diante dessa dificuldade, uma das alternativas é a utilização de meliáceas exóticas, como as espécies do gênero Khaya, conhecidas comumente por mogno africano que produzem madeira de ótima qualidade.

Segundo Falesi \& Baena ( 1999), o mogno africano (K. ivorensis) tem sido uma das espécies preferidas pelos reflorestadores no estado do Pará. É uma árvore de grande importância devido ao seu alto valor no comércio internacional e crescimento relativamente rápido, promovendo a recuperação de áreas alteradas, além de oferecer resistência a algumas pragas, como a broca do ponteiro (H. grandella) (LEMMENS, 2008; VERZIGNASSI et al., 2009).

Para que uma planta se desenvolva e expresse todo o seu potencial produtivo, é necessário um correto suprimento de nutrientes. Além dos macronutrientes orgânicos, carbono, hidrogênio e oxigênio, os quais constituem o maior peso da planta verde ou da sua matéria seca, é preciso considerar também os sais minerais que, embora sejam requeridos em pequenas quantidades, são fundamentais para o desempenho das principais funções metabólicas da célula (MALAVOLTA et al., 1997). Assim, o adequado suprimento desses nutrientes é ponto chave para o crescimento e desenvolvimento de espécies florestais, bem como de outras plantas.

A espécie $K$. ivorensis, embora tenha se destacado como uma boa opção na produção de madeira, ainda são poucos os trabalhos que apontam as necessidades nutricionais dessa espécie quando em cultivo comercial. Assim, considerando o que foi exposto, o presente trabalho teve como objetivo estudar os aspectos relacionados à nutrição mineral em mudas de mogno africano (Khaya ivorensis), avaliando o desenvolvimento e a composição mineral das plantas submetidas à omissão dos macronutrientes nitrogênio, fósforo, potássio, cálcio, magnésio e enxofre; e dos micronutrientes: ferro, boro, cobre, manganês, zinco e molibdênio em mudas prontas para plantio.

\section{MATERIAL E MÉTODOS}

O experimento foi conduzido em viveiro localizado em Goiânia, GO, cujas coordenadas geográficas são: latitude de 1642’27'S, longitude 49²l'0I'W e altitude de 764 metros. A região encontra-se na Bacia do Paranaíba, com clima do tipo Aw (Clima Tropical com estação seca de inverno), segundo a classificação de Köppen (SEPIN, 2003).

Foram utilizadas mudas comerciais de Khaya ivorensis produzidas no Viveiro Mudas Nobres, provenientes de sementes oriundas de árvores adultas cultivadas no município de Paragominas no Estado do Pará. Para a produção de mudas comerciais o viveiro utiliza tubetes de polipropileno com capacidade para I 80 $\mathrm{cm}^{3}$ de substrato comercial (Ouro Negro Germinação) constituído por $40 \%$ de casca de pinus, $20 \%$ de fibra e pó de coco, $30 \%$ de cinza de bagaço de cana e 10\% de vermiculita. As adubações foram realizadas (via irrigações) a cada dez dias durante todo o período de desenvolvimento das mudas, até estas atingirem o ponto de plantio a, aproximadamente, 150 dias após a semeadura.

O transplantio das mudas ocorreu aos 125 dias após a emergência, sendo estas retiradas dos tubetes de $180 \mathrm{~cm}^{3}$ e transferidas para tubetes de polipropileno com capacidade para 3,8 litros (Citrospote) contendo como substrato areia grossa lavada. Os tubetes e as mudas transplantadas foram acondicionadas em mesas metálicas e mantidas em casa de vegetação por quinze dias, sendo irrigadas apenas com água. Após esse período em casa de vegetação, as plantas permaneceram sob sombrite (50\%) por sete dias para iniciar o processo de rustificação e, posteriormente, foram colocadas a pleno sol, sendo irrigadas diariamente com solução nutritiva (Tabela I). As composições das soluções nutritivas foram adaptadas de acordo com Sarruge (1975) e Jacobson (195I).

Os tratamentos avaliados nas parcelas foram os seguintes: TI-Solução completa (nitrogênio, fósforo, potássio, cálcio, magnésio, enxofre, ferro, boro, cobre, manganês, zinco e molibdênio); T2-Solução completa, com omissão de N; T3-Solução completa, com omissão de P; T4-Solução completa, com omissão de K; T5Solução completa, com omissão de Ca; T6-Solução completa, com omissão de Mg; T7-Solução completa, com omissão de S; T8-Solução completa, com omissão 
TABELA 1 Composição das soluções nutritivas, em $\mathrm{ml} \cdot \mathrm{L}^{-1}$, utilizadas para avaliar a nutrição mineral em mudas de Khaya ivorensis. TABLE 1 Composition of nutrient solutions, in $\mathrm{ml} \cdot \mathrm{L}^{-1}$, used to evaluate the mineral nutrition in seedlings Khaya ivorensis. Tratamentos

Omissão de nutriente $\left(\mathrm{ml} \cdot \mathrm{L}^{-1}\right)$

\begin{tabular}{|c|c|c|c|c|c|c|c|c|c|c|c|c|c|}
\hline Solução Estoque & 1 & 2 & 3 & 4 & 5 & 6 & 7 & 8 & 9 & 10 & 11 & 12 & 13 \\
\hline $1 \mathrm{ml} \cdot \mathrm{L}^{-1}$ & Completo & $-N$ & $-P$ & $-\mathrm{K}$ & $-\mathrm{Ca}$ & $-M g$ & $-S$ & $-\mathrm{Fe}$ & $-B$ & - $\mathrm{Cu}$ & $-M n$ & $-Z n$ & - Mo \\
\hline $\mathrm{KH}_{2} \mathrm{PO}_{4}$ & 1 & 1 & - & - & 1 & 1 & 1 & 1 & 1 & 1 & 1 & 1 & 1 \\
\hline $\mathrm{KNO}_{3}$ & 5 & - & 5 & - & 5 & 3 & 3 & 5 & 5 & 5 & 5 & 5 & 5 \\
\hline $\mathrm{Ca}\left(\mathrm{NO}_{3}\right)_{2}$ & 5 & - & 5 & 5 & - & 4 & 4 & 5 & 5 & 5 & 5 & 5 & 5 \\
\hline $\mathrm{MgSO}_{4}$ & 2 & 2 & 2 & 2 & 2 & - & - & 2 & 2 & 2 & 2 & 2 & 2 \\
\hline $\mathrm{KCl}$ & - & 5 & 1 & - & - & 2 & 2 & - & - & - & - & - & - \\
\hline $\mathrm{CaCl}_{2}$ & - & 5 & - & - & - & 1 & 1 & - & - & - & - & - & - \\
\hline $\mathrm{NH}_{4} \mathrm{H}_{2} \mathrm{PO}_{4}$ & - & - & - & 1 & - & - & - & - & - & - & - & - & - \\
\hline $\mathrm{NH}_{4} \mathrm{NO}_{3}^{4}$ & - & - & - & 2 & 5 & - & - & - & - & - & - & - & - \\
\hline$\left(\mathrm{NH}_{4}^{4}\right) \mathrm{SO}_{4}^{3}$ & - & - & - & - & - & 2 & - & - & - & - & - & - & - \\
\hline $\mathrm{Mg}\left(\mathrm{NO}_{3}\right)_{2}^{4}$ & - & - & - & - & - & - & 2 & - & - & - & - & - & - \\
\hline \multicolumn{14}{|c|}{ Micronutrientes } \\
\hline Micro - Fe ${ }^{1}$ & 1 & 1 & 1 & 1 & 1 & 1 & 1 & 1 & - & - & - & - & - \\
\hline Micro - B & - & - & - & - & - & - & - & - & 1 & - & - & - & - \\
\hline Micro - Cu & - & - & - & - & - & - & - & - & - & 1 & - & - & - \\
\hline Micro - Mn & - & - & - & - & - & - & - & - & - & - & 1 & - & - \\
\hline Micro - Zn & - & - & - & - & - & - & - & - & - & - & - & 1 & - \\
\hline Micro - Mo & - & - & - & - & - & - & - & - & - & - & - & - & 1 \\
\hline Fe-EDTA ${ }^{2}$ & 1 & 1 & 1 & 1 & 1 & 1 & 1 & - & 1 & 1 & 1 & 1 & 1 \\
\hline
\end{tabular}

${ }_{1}^{1}$ Solução Estoque de Micronutrientes: $2,86 \mathrm{~g} \cdot \mathrm{L}^{-1}$ de $\mathrm{H}_{3} \mathrm{BO}_{3} ; 20,820 \mathrm{~g} \cdot \mathrm{L}^{-1}$ de $\mathrm{MnCl}_{2} \cdot 4 \mathrm{H}_{2} \mathrm{O} ; 0,146 \mathrm{~g} \cdot \mathrm{L}^{-1}$ de $\mathrm{ZnCl}_{2} 3 \mathrm{H}_{2} \mathrm{O} ; 0,055 \mathrm{~g} \cdot \mathrm{L}^{-1}$ de $\mathrm{CuCl}_{2} 2 \mathrm{H}_{2} \mathrm{O} ; 0,027$ g. $\mathrm{L}^{-1}$ de $\mathrm{Na}_{2} \mathrm{MoO}_{4} \cdot 2 \mathrm{H}_{2} \mathrm{O}$.

${ }^{2} \mathrm{Fe}$-EDTA: $33,2 \mathrm{~g} \cdot \mathrm{L}^{-1}$ de EDTA; $89,2 \mathrm{~g} \cdot \mathrm{L}^{-1}$ de $\mathrm{NaOH} ; 24,9 \mathrm{~g} \cdot \mathrm{L}^{-1}$ de $\mathrm{FeSO}_{4}$.

de Fe; T9-Solução completa, com omissão de B; TI0Solução completa, com omissão de Cu; TII-Solução completa, com omissão de Mn; TI2-Solução completa, com omissão de Zn; TI3-Solução completa, com omissão de Mo; TI4-Água deionizada (sem nutrientes).

As plantas foram irrigadas diariamente com 200 $\mathrm{ml}$ de solução nutritiva, sendo aplicados $100 \mathrm{ml}$ no período da manhã e $100 \mathrm{ml}$ no período da tarde. As soluções nutritivas eram renovadas a cada 20 dias. Os dados referentes à altura total e ao diâmetro na região do coleto das plantas foram obtidos a cada quinze dias até $\circ$ final dos ensaios. Os sintomas de deficiência dos nutrientes nas mudas foram descritos desde o estágio inicial até tornarem-se bem definidos, aos 220 dias após o transplantio destas, quando foram retiradas dos tubetes. Ao final do experimento, as folhas foram colocadas para secar em estufa com ventilação forçada a $65^{\circ} \mathrm{C}$, até peso constante. Após a secagem, todo o material foi pesado para determinação da massa de matéria seca (MMS) e moído para determinação dos teores de macronutrientes e micronutrientes. $O$ delineamento experimental utilizado foi o inteiramente casualizado, com quatorze tratamentos, dez repetições e parcelas constituídas com uma planta por tubete.

A análise estatística consistiu da análise de variância, com aplicação do teste $\mathrm{Fe}$, quando constatadas diferenças significativas, aplicou-se o teste Tukey a $1 \%$ e a $5 \%$ de probabilidade, utilizando-se o Programa Sanest (1995).

\section{RESULTADOS E DISCUSSÃO}

Observa-se, na Tabela 2, que as análises de variância indicaram efeitos significativos dos tratamentos contendo, ou não, macronutrientes e micronutrientes na solução nutritiva, em todas as variáveis relativas ao desenvolvimento das mudas de mogno africano (Khaya ivorensis).

$\mathrm{Na}$ Tabela 3 são apresentados os resultados de altura da planta e diâmetro do coleto, de plantas de mogno africano submetidas a diversos tratamentos com presença e ausência de nutrientes. Constata-se que houve redução significativa da altura e do diâmetro do coleto das plantas nos tratamentos com omissão de $\mathrm{Ne}$ testemunha, quando comparados com os valores obtidos no tratamento completo. Resultados semelhantes foram observados por Silveira et al. (2002) em clones de eucalipto, em que a ausência do nitrogênio foi o tratamento que mais afetou o crescimento das plantas.

Em experimento com mudas de umbuzeiro sob omissão de macronutrientes, Gonçalves et al. (2006) observaram as maiores reduções na altura das plantas nos tratamentos com omissões de $\mathrm{Ca}, \mathrm{N}$ e $\mathrm{Mg}$. Em relação ao diâmetro, ocorreu fato semelhante ao observado com a altura, sendo que as plantas, nos tratamentos com omissão de $\mathrm{Ca}, \mathrm{N}, \mathrm{Mg}$ e $\mathrm{K}$ apresentaram caules mais finos. Outros trabalhos apontam o $\mathrm{N}$ e $\circ \mathrm{Ca}$ como os elementos mais limitantes ao crescimento em altura e diâmetro do caule de outras espécies, como timbó (Indigofera lespedezoides) (CONCEIÇÃO et al., 2002) e graviola (Anona muricata) (BATISTA et al., 2003). 
TABELA 2 Resumo das análises de variância para altura da planta (AP), diâmetro do coleto (DC) e matéria seca das folhas (MSF), do caule (MSC) e total da parte aérea (MSPA) de mudas de Khaya ivorensis submetidas a diferentes tratamentos com presença e ausência de nutrientes na solução nutritiva, a partir dos 60 dias após a semeadura.

TABLE 2 Summary of analysis of variance for plant height (AP), stem diameter (DC) and dry matter of leaves (MSF), the stem (MSC) and total shoot (MSPA) of Khaya ivorensis seedlings submitted to different treatments with and without nutrients in the nutrient solution, from 60 days after sowing.

\begin{tabular}{ccccccc}
\hline \multirow{2}{*}{$\begin{array}{c}\text { Fonte de } \\
\text { variação }\end{array}$} & \multirow{2}{*}{ Graus de liberdade } & \multicolumn{4}{c}{ Valores do quadrado médio do resíduo e níveis de significância pelo teste F } \\
\cline { 3 - 7 } & & $\mathrm{AP}(\mathrm{cm})$ & $\mathrm{DC}(\mathrm{mm})$ & $\mathrm{MSF}(\mathrm{g})$ & $\mathrm{MSC}(\mathrm{g})$ & $\mathrm{MSPA}(\mathrm{g})$ \\
\hline Tratamento & 13 & $375,15^{* *}$ & $9,06^{* *}$ & $160,69^{* *}$ & $330,13^{* *}$ & $937,51^{* *}$ \\
Resíduo & 126 & 48,13 & 1,494 & 11,903 & 33,460 & 65,180 \\
\hline Total & 139 & & & & 30,80 & 25,30 \\
\hline CV $(\%)$ & & 13,90 & 10,600 & 27,700 & 30 \\
\hline
\end{tabular}

** significativo pelo teste $\mathrm{F}$ a $1 \%$ de probabilidade.

Resultados parcialmente semelhantes foram observados por Maffeis et al. (2000) em plantas de Eucalyptus citriodora tratadas com soluções nutritivas omitindo $\mathrm{N}, \mathrm{Ca}, \mathrm{Mg}, \mathrm{S}$ e $\mathrm{B}$, tendo apresentado menor crescimento em altura quando comparado aos valores avaliados com a aplicação de solução completa. Em relação ao diâmetro de coleto, houve redução significativa apenas no tratamento sem $\mathrm{N}$.

Os resultados encontrados na presente pesquisa, para os tratamentos com omissão de $\mathrm{Ca}, \mathrm{Mg}$ e $\mathrm{B}$, contrariam os resultados descritos por Maffeis et al. (2000), sendo as alturas médias das plantas equiparadas aos valores registrados no tratamento completo. Em relação ao diâmetro do coleto, o tratamento sem $\mathrm{Ca}$ propiciou resultado semelhante ao tratamento completo, e os tratamentos com omissão de $\mathrm{Mg}$ e $\mathrm{B}$ proporcionaram alturas de plantas com valores um pouco abaixo dos obtidos no tratamento Completo (Tabela 3), demonstrando uma menor exigência de Ca e Mg por plantas desta espécie.

De acordo com Gonçalves et al. (2006), os dados de crescimento obtidos no tratamento com omissão de $P$ indicam menor exigência desse nutriente na fase inicial de crescimento do umbuzeiro, sendo o $\mathrm{P}$ da reserva da raiz, somado ao $\mathrm{P}$ absorvido na fase de adaptação (solução completa), suficientes para manter crescimento similar ao da testemunha, o que está de acordo com o que foi observado no presente trabalho.

A omissão dos diversos micronutrientes, exceto o macronutriente $\mathrm{N}$, não influenciou o crescimento das plantas de $K$. ivorensis, provavelmente porque durante a etapa inicial, onde as plantas foram mantidas em substrato comercial, o suprimento desses micronutrientes foi suficiente para sustentar o crescimento posterior da planta durante o período experimental.

Os valores médios de matéria seca de folha, do caule e total, aos 220 dias após o transplantio de plantas de $K$. ivorensis supridas com solução nutritiva completa e com omissão de nutrientes estão apresentados na Tabela 4.
Observa-se que os tratamentos com omissão de $\mathrm{N}$ e testemunha apresentaram valores significativamente menores de matéria seca de folha, do caule e total em comparação com os valores do tratamento completo. A produção de matéria seca total ocorreu na seguinte ordem decrescente: $\mathrm{Ca}>\mathrm{Mg}>\mathrm{Mo}>\mathrm{Cu}>\mathrm{Mn}>\mathrm{K}$ $>\mathrm{Zn}>$ completo $>\mathrm{S}>\mathrm{P}>\mathrm{B}>\mathrm{Fe}>$ testemunha $>$ $\mathrm{N}$, destacando-se o $\mathrm{N}$ como elemento mais limitante ao crescimento inicial e $\mathrm{Ca}, \mathrm{Mg}$ e Mo os menos exigidos na fase inicial de desenvolvimento da planta.

TABELA 3 Altura média e diâmetro médio do coleto de plantas de Khaya ivorensis, aos 220 dias após o transplantio, supridas com solução nutritiva completa e com omissão de nutrientes.

TABLE 3 Average height and diameter of the root collar of Khaya ivorensis plants, 220 days after transplanting, supplied with complete nutrient solution and with omission of nutrients.

\begin{tabular}{lcc}
\hline \multicolumn{1}{c}{ Tratamentos } & $\begin{array}{c}\text { Altura de planta } \\
(\mathrm{cm})\end{array}$ & $\begin{array}{c}\text { Diâmetro de coleto } \\
(\mathrm{mm})\end{array}$ \\
\hline 1-Completo & $51,60^{\mathrm{a}}$ & $12,30^{\mathrm{a}}$ \\
2-Omissão de nitrogênio & $37,90^{\mathrm{bc}}$ & $9,80^{\mathrm{bc}}$ \\
3-Omissão de fósforo & $51,20^{\mathrm{a}}$ & $11,70^{\mathrm{a}}$ \\
4-Omissão de potássio & $49,00^{\mathrm{a}}$ & $11,80^{\mathrm{a}}$ \\
5-Omissão de cálcio & $55,70^{\mathrm{a}}$ & $12,30^{\mathrm{a}}$ \\
6-Omissão de magnésio & $56,70^{\mathrm{a}}$ & $12,20^{\mathrm{a}}$ \\
7-Omissão de enxofre & $47,10^{\mathrm{abc}}$ & $11,40^{\mathrm{ab}}$ \\
8-Omissão de ferro & $48,80^{\mathrm{a}}$ & $12,00^{\mathrm{a}}$ \\
9-Omissão de boro & $53,40^{\mathrm{a}}$ & $11,70^{\mathrm{a}}$ \\
10-Omissão de cobre & $55,60^{\mathrm{a}}$ & $12,00^{\mathrm{a}}$ \\
11-Omissão de manganês & $53,90^{\mathrm{a}}$ & $11,80^{\mathrm{a}}$ \\
12-Omissão de zinco & $48,50^{\mathrm{ab}}$ & $11,10^{\mathrm{abc}}$ \\
13-Omissão de molibdênio & $53,80^{\mathrm{a}}$ & $12,70^{\mathrm{a}}$ \\
14-Testemunha & $36,80^{\mathrm{c}}$ & $9,30^{\mathrm{c}}$ \\
\hline \multicolumn{1}{c}{ CV (\%) } & $13,8^{\mathrm{a}}$ & $10,5^{\mathrm{a}}$ \\
\hline
\end{tabular}

*Médias seguidas de letras minúsculas iguais, na mesma coluna, não diferem entre si pelo teste de Tukey, ao nível de $5 \%$. 
TABELA 4 Matéria seca das folhas, do caule e total da parte aérea de plantas de Khaya ivorensis, aos 220 dias após o transplantio, supridas com solução nutritiva completa e com omissão de nutrientes.

TABLE 4 Leaf, stem, and total shoot dry matter of Khaya ivorensis plants, 220 days after transplanting, supplied with complete nutrient solution and with omission of nutrients

\begin{tabular}{|c|c|c|c|}
\hline \multirow{2}{*}{ Tratamentos } & \multicolumn{3}{|c|}{ Matéria seca $(\mathrm{g})$} \\
\hline & Folha & Caule & Total parte aérea \\
\hline 1-Completo & $12,10 \mathrm{abc}$ & $20,30 a b c$ & $33,00^{\mathrm{bcd}}$ \\
\hline $\begin{array}{l}\text { 2-Omissão de } \\
\text { nitrogênio }\end{array}$ & $5,40^{d}$ & $8,70^{d}$ & $14,80^{e}$ \\
\hline 3-Omissão de fósforo & $10,60 \mathrm{bcd}$ & $16,50 \mathrm{bcd}$ & $27,60^{\mathrm{cd}}$ \\
\hline 4-Omissão de potássio & $15,90^{\text {a }}$ & $18,70 \mathrm{bc}$ & $34,90 \mathrm{abcd}$ \\
\hline 5-Omissão de cálcio & $17,00^{a}$ & $28,30^{a}$ & $45,70^{a}$ \\
\hline $\begin{array}{l}\text { 6-Omissão de } \\
\text { magnésio }\end{array}$ & $17,30^{a}$ & $24,80^{a b}$ & $44,20 \mathrm{ab}$ \\
\hline 7-Omissão de enxofre & $9,80^{c d}$ & $17,70 \mathrm{bc}$ & $28,60^{\mathrm{cd}}$ \\
\hline 8-Omissão de ferro & $9,60^{\mathrm{cd}}$ & $15,30 \mathrm{~cd}$ & 24,80 de \\
\hline 9-Omissão de boro & $9,40^{\text {cd }}$ & $16,00 \mathrm{bcd}$ & 26,00 de \\
\hline 10-Omissão de cobre & $15,80^{a b}$ & $23,50 a b c$ & 39,80 abc \\
\hline $\begin{array}{l}\text { 11-Omissão de } \\
\text { manganês }\end{array}$ & $14,50 \mathrm{abc}$ & $21,60 a b c$ & 36,40 abcd \\
\hline 12-Omissão de zinco & $14,50 \mathrm{abc}$ & $18,20^{\mathrm{bc}}$ & $33,40 \mathrm{abcd}$ \\
\hline $\begin{array}{l}\text { 13-Omissão de } \\
\text { molibdênio }\end{array}$ & $16,50^{\text {a }}$ & 24,60 ab & $41,70 \mathrm{ab}$ \\
\hline 14-Testemunha & $6,20^{d}$ & $8,40^{d}$ & $15,20^{e}$ \\
\hline CV (\%) & 27,6 & 30,8 & 25,3 \\
\hline
\end{tabular}

*Médias seguidas de letras minúsculas iguais, na mesma coluna, não diferem entre si pelo teste de Tukey, ao nível de $5 \%$.

Em mudas de mogno brasileiro (S. macrophylla), Wallau et al. (2008) observaram redução na matéria seca total nos tratamentos com omissão de $\mathrm{N}, \mathrm{K}, \mathrm{Ca}$ e $\mathrm{Cu}$, indicando maior demanda desses nutrientes na fase inicial de desenvolvimento da planta. Gonçalves et al. (2006) constataram que as omissões de $\mathrm{Ca}, \mathrm{N}, \mathrm{K}$ e $\mathrm{Mg}$ ocasionaram decréscimo na produção de matéria seca de raiz, folha, caule e total, em relação aos demais tratamentos, enquanto que os tratamentos com omissão de $\mathrm{P}$ e $\mathrm{S}$ não diferiram significativamente do tratamento completo, indicando que, no período avaliado, esses dois nutrientes não limitaram a produção de matéria seca total das plantas de umbuzeiro.

Em experimento com Acacia holosericea, Sarcinelli et al. (2004) verificaram que o decréscimo na produção da matéria vegetal ocorreu nos tratamentos com omissão de N, Mg, K e S, e Dias et al. (1990) constataram baixas exigências de Ca para a formação de mudas de $A$. mangium, outra espécie deste mesmo gênero.
Segundo Viégas et al. (2004), em experimento com camucamuzeiro, os tratamentos que mais afetaram a produção de matéria seca total foram os com omissões individuais de $\mathrm{N}, \mathrm{K}$ e $\mathrm{B}$, quando comparados ao tratamento completo.

Foi constatado, por Salvador et al. (1999), que as deficiências de $\mathrm{B}, \mathrm{Cu}, \mathrm{Fe}, \mathrm{Mn}$ e $\mathrm{Zn}$ induziram ao decréscimo da produção de matéria seca de mudas de goiabeira, concluindo que o desenvolvimento da planta foi menos afetado pela carência de $\mathrm{Mn}$ e mais afetada pelo $\mathrm{Fe}$. De acordo com os resultados do presente estudo, os micronutrientes $\mathrm{B}$ e Fe foram os que mais afetaram a produção de matéria, concordando com os resultados encontrados por Salvador et al. (1999).

Encontram-se, na Tabela 5, os teores dos macronutrientes $\mathrm{N}, \mathrm{P}, \mathrm{K}, \mathrm{Ca}$ e $\mathrm{Mg}$ nas folhas de plantas de Khaya ivorensis supridas com solução nutritiva completa e com omissão de nutrientes.

Verifica-se que os teores de nitrogênio nas folhas foram menores e com significância estatística apenas no tratamento Testemunha, quando comparado ao tratamento Completo. Menores teores foliares de P, $\mathrm{Ke}$ Ca ocorreram quando esses elementos foram omitidos na solução nutritiva, sendo os valores de $\mathrm{P}$ e $\mathrm{K}$ equiparados aos do tratamento testemunha. $\mathrm{Na}$ ausência de $\mathrm{Mg}$, os teores foliares desse elemento foram superiores mas não significativos em relação ao tratamento completo,

TABELA 5 Teores dos macronutrientes nitrogênio, fósforo, potássio, cálcio e magnésio nas folhas de plantas de Khaya ivorensis supridas com solução nutritiva completa e com omissão de nutrientes

TABLE 5 Levels of the macronutrients nitrogen, phosphorus, potassium, calcium, and magnesium in the leaves of Khaya ivorensis plants supplied with a complete nutrient solution and with omission of nutrients.

\begin{tabular}{lccccc}
\hline \multirow{2}{*}{ Tratamentos } & \multicolumn{5}{c}{ Macronutrientes $\left(\mathrm{g}^{\circ} \mathrm{Kg}^{-1}\right)$} \\
\cline { 2 - 6 } & $\mathrm{N}$ & $\mathrm{P}$ & $\mathrm{K}$ & $\mathrm{Ca}$ & $\mathrm{Mg}$ \\
\hline Completo & $32,60^{\mathrm{a}}$ & $1,30^{\text {ef }}$ & $8,30^{\mathrm{ef}}$ & $12,00^{\mathrm{de}}$ & $2,40^{\mathrm{b}}$ \\
Sem N & $25,90^{\mathrm{a}}$ & $2,20^{\mathrm{cde}}$ & $9,90^{\mathrm{cde}}$ & $21,50^{\mathrm{bc}}$ & $5,80^{\mathrm{a}}$ \\
Sem P & $33,10^{\mathrm{a}}$ & $1,10^{\mathrm{f}}$ & $11,10^{\mathrm{abc}}$ & $12,50^{\mathrm{d}}$ & $2,30^{\mathrm{b}}$ \\
Sem K & $29,00^{\mathrm{a}}$ & $3,60^{\mathrm{ab}}$ & $6,10^{\mathrm{g}}$ & $19,90^{\mathrm{bc}}$ & $4,80^{\mathrm{a}}$ \\
Sem Ca & $27,60^{\mathrm{a}}$ & $3,30^{\mathrm{ab}}$ & $10,60^{\mathrm{bcd}}$ & $6,80^{\mathrm{e}}$ & $4,90^{\mathrm{a}}$ \\
Sem Mg & $25,60^{\mathrm{a}}$ & $3,30^{\mathrm{ab}}$ & $11,20^{\mathrm{abc}}$ & $19,40^{\mathrm{bc}}$ & $3,20^{\mathrm{b}}$ \\
Sem S & $25,60^{\mathrm{a}}$ & $2,90^{\mathrm{bcd}}$ & $10,40^{\mathrm{bcd}}$ & $21,40^{\mathrm{bc}}$ & $5,10^{\mathrm{a}}$ \\
Sem Fe & $27,90^{\mathrm{a}}$ & $4,00^{\mathrm{a}}$ & $11,90^{\mathrm{ab}}$ & $31,90^{\mathrm{a}}$ & $5,50^{\mathrm{a}}$ \\
Sem B & $26,80^{\mathrm{a}}$ & $3,10^{\mathrm{abc}}$ & $11,90^{\mathrm{ab}}$ & $20,80^{\mathrm{bc}}$ & $2,60^{\mathrm{b}}$ \\
Sem Cu & $27,90^{\mathrm{a}}$ & $2,10^{\mathrm{de}}$ & $11,70^{\mathrm{ab}}$ & $16,50^{\mathrm{cd}}$ & $2,80^{\mathrm{b}}$ \\
Sem Mn & $28,60^{\mathrm{a}}$ & $1,70^{\text {ef }}$ & $12,40^{\mathrm{a}}$ & $16,90^{\mathrm{bcd}}$ & $3,00^{\mathrm{b}}$ \\
Sem Zn & $28,70^{\mathrm{a}}$ & $1,80^{\text {ef }}$ & $11,50^{\mathrm{abc}}$ & $18,60^{\mathrm{bc}}$ & $3,00^{\mathrm{b}}$ \\
Sem Mo & $27,60^{\mathrm{a}}$ & $1,50^{\text {ef }}$ & $9,20^{\mathrm{de}}$ & $18,90^{\mathrm{bc}}$ & $2,90^{\mathrm{b}}$ \\
Testemunha & $11,20^{\mathrm{b}}$ & $1,00^{\mathrm{f}}$ & $7,40^{\mathrm{fg}}$ & $22,30^{\mathrm{b}}$ & $5,40^{\mathrm{a}}$ \\
\hline \multicolumn{1}{c}{ CV (\%) } & $19,30^{\circ}$ & 26,80 & $11,10^{\circ}$ & 19,8 & 23,5 \\
\hline
\end{tabular}

*Médias seguidas de letras minúsculas iguais, na mesma coluna, não diferem entre si pelo teste de Tukey ao nível de $5 \%$. 
enquanto os teores de $\mathrm{P}$ foram maiores na ausência de $\mathrm{N}, \mathrm{Ca}, \mathrm{Mg}, \mathrm{S}, \mathrm{Fe}, \mathrm{B}$ e $\mathrm{Cu}$, os teores de $\mathrm{K}$ mais elevados na ausência de $\mathrm{P}, \mathrm{Ca}, \mathrm{Mg}, \mathrm{S}, \mathrm{Fe}, \mathrm{B}, \mathrm{Cu}, \mathrm{Mn}$ e $\mathrm{Zn}$, os teores de Ca mais altos na ausência de N, K, Mg, S, Fe, B, Zn, Mo e no tratamento testemunha, e teores maiores de $\mathrm{Mg}$ na ausência de N, K, Ca, S, Fe e no tratamento Testemunha.

Avaliando substâncias nutritivas em mudas de cerejeira, Vieira et al. (20l I) também observaram que a omissão de Ca e K aumentaram a concentração de $\mathrm{P}$ nas plantas, corroborando com resultados encontrados no presente trabalho.

O teor de potássio encontrado no tratamento completo ficou abaixo dos valores obtidos nos demais tratamentos, com exceção dos tratamentos testemunha e com omissão de potássio. A redução nos teores de potássio encontrados nas folhas de $K$. ivorensis obedecem à seguinte ordem: $\mathrm{K}>$ Testemunha $>$ Completo $>$ Mo $>\mathrm{N}>\mathrm{S}>\mathrm{Ca}>\mathrm{P}>\mathrm{Mg}>\mathrm{Zn}>\mathrm{Cu}>\mathrm{Fe}>\mathrm{B}>\mathrm{Mn}$.

No tratamento completo o teor de cálcio analisado nas plantas de mogno africano, também seguiu a mesma tendência, apresentando-se abaixo dos valores de todos os outros tratamentos, com exceção do tratamento sem Ca. No tratamento testemunha o teor de cálcio foi o segundo maior, apresentando diferença significativa quando comparado ao tratamento completo. A redução nos teores de cálcio encontrados nas folhas de $K$. ivorensis, obedecem a seguinte ordem: $\mathrm{Ca}>$ completo $>\mathrm{P}>\mathrm{Cu}>\mathrm{Mn}>\mathrm{Zn}>$ $\mathrm{Mo}>\mathrm{Mg}>\mathrm{K}>\mathrm{B}>\mathrm{S}>\mathrm{N}>$ testemunha $>\mathrm{Fe}$.

O magnésio, no tratamento completo, apresentou teores abaixo dos valores obtidos em todos os outros tratamentos, com exceção do tratamento com omissão de $P$. A redução nos teores de magnésio, encontrados nas folhas de $K$. ivorensis, obedecem a seguinte ordem: $\mathrm{P}>$ completo $>\mathrm{B}>\mathrm{Cu}>\mathrm{Mo}>\mathrm{Mn}>\mathrm{Zn}>\mathrm{Mg}>\mathrm{K}$ $>\mathrm{Ca}>\mathrm{S}>$ testemunha $>\mathrm{Fe}>\mathrm{N}$. Com exceção do $\mathrm{K}$, os teores de macronutrientes obtidos nas plantas de mogno africano supridas com solução nutritiva completa ficaram acima ou dentro da faixa considerada adequada por Malavolta et al. (1997), indicando grande exigência nutricional desta espécie.

$\mathrm{Na}$ Tabela 6 encontram-se os teores dos micronutrientes $\mathrm{Fe}, \mathrm{Cu}, \mathrm{Mn}$ e $\mathrm{Zn}$ analisados nas folhas de plantas de $K$. ivorensis supridas com solução nutritiva completa e com omissão de nutrientes.

Os teores foliares de ferro foram significativamente menores nos tratamentos com omissão de $\mathrm{Mg}, \mathrm{S}$ e Fe em relação ao tratamento completo. As maiores concentrações de Fe foram observadas nos tratamentos completo, testemunha e com omissões de Zn e Mo. Contata-se que os teores foliares de cobre não diferiram significativamente entre o tratamento Completo e aquele com omissão deste elemento. Os maiores teores de cobre foram encontrados nos tratamentos com omissão de $\mathrm{Ca}$, Mo e testemunha, que diferiram significativamente do tratamento completo, e este último apresentou 0 menor teor de cobre.

Os teores foliares de $M n$ também não diferiram significativamente entre o tratamento completo e aquele com a omissão deste elemento. O maior teor de $\mathrm{Mn}$ foi obtido no tratamento com omissão de $\mathrm{Ca}$, diferindo estatisticamente dos valores dos demais tratamentos. O zinco analisado nas folhas das plantas apresentou seus maiores teores nos tratamentos com omissão de $\mathrm{N}, \mathrm{P}, \mathrm{K}$ e completo, e menores teores nos tratamentos com omissão de $\mathrm{Zn}, \mathrm{Cu}, \mathrm{S}, \mathrm{Fe}, \mathrm{Mn}, \mathrm{B}, \mathrm{Mg}, \mathrm{Mo}$, Ca e testemunha, que diferiram significativamente dos valores obtidos no tratamento completo.

Nesta pesquisa, os teores de $\mathrm{Fe}$ analisados ficaram bem superiores aos descritos por Malavolta et al. (1997) para espécies florestais, indicando grande exigência nutricional das plantas de mogno africano por esse micronutriente. Os teores de $\mathrm{Mn}$ e $\mathrm{Zn}$ obtidos se encontram dentro da faixa de concentração considerada adequada pela literatura, e os teores de cobre ficaram um pouco abaixo da faixa considerada adequada para espécies florestais, de acordo com a referida fonte.

TABELA 6 Teores dos micronutrientes ferro, cobre, manganês e zinco nas folhas de plantas de Khaya ivorensis supridas com solução nutritiva completa e com omissão de nutrientes.

TABLE 6 Levels of the micronutrients iron, copper, manganese, and zinc in the leaves of Khaya ivorensis plants supplied with a complete nutrient solution and with omission of nutrients.

\begin{tabular}{lcccc}
\hline \multirow{2}{*}{ Tratamentos } & \multicolumn{4}{c}{ Micronutrientes $\left(\mathrm{mg} \mathrm{Kg}^{-1}\right)$} \\
\cline { 2 - 5 } & $\mathrm{Fe}$ & $\mathrm{Cu}$ & $\mathrm{Mn}$ & $\mathrm{Zn}$ \\
\hline Completo & $521,2^{\mathrm{abc}}$ & $2,30^{\mathrm{d}}$ & $50,20^{\mathrm{cde}}$ & $15,40^{\mathrm{a}}$ \\
Sem N & $467,2^{\mathrm{cd}}$ & $2,60^{\mathrm{bcd}}$ & $48,20^{\mathrm{cde}}$ & $15,30^{\mathrm{ab}}$ \\
Sem P & $446,0^{\mathrm{cd}}$ & $2,60^{\mathrm{bcd}}$ & $43,60^{\mathrm{de}}$ & $15,90^{\mathrm{a}}$ \\
Sem K & $492,2^{\mathrm{bc}}$ & $2,50^{\mathrm{cd}}$ & $82,10^{\mathrm{bcd}}$ & $16,10^{\mathrm{a}}$ \\
Sem Ca & $450,6^{\mathrm{cd}}$ & $3,90^{\mathrm{a}}$ & $157,20^{\mathrm{a}}$ & $11,00^{\mathrm{cd}}$ \\
Sem Mg & $371,8^{\mathrm{de}}$ & $3,50^{\mathrm{bbcd}}$ & $93,50^{\mathrm{b}}$ & $9,80^{\mathrm{cdef}}$ \\
Sem S & $325,3^{\mathrm{e}}$ & $2,50^{\mathrm{cd}}$ & $40,20^{\mathrm{a}}$ & $6,40^{\mathrm{gh}}$ \\
Sem Fe & $343,5^{\mathrm{e}}$ & $2,70^{\mathrm{abcd}}$ & $41,40^{\mathrm{e}}$ & $6,80^{\mathrm{fgh}}$ \\
Sem B & $468,8^{\mathrm{cd}}$ & $2,90^{\mathrm{abcd}}$ & $84,20^{\mathrm{bc}}$ & $7,20^{\mathrm{efg}}$ \\
Sem Cu & $454,2^{\mathrm{cd}}$ & $3,00^{\mathrm{abcd}}$ & $82,90^{\mathrm{bcd}}$ & $3,80^{\mathrm{h}}$ \\
Sem Mn & $452,8^{\mathrm{cd}}$ & $3,00^{\mathrm{abcd}}$ & $78,30^{\mathrm{bcde}}$ & $7,00^{\mathrm{fg}}$ \\
Sem Zn & $530,7^{\mathrm{abc}}$ & $3,30^{\mathrm{abcd}}$ & $72,00^{\mathrm{bcde}}$ & $8,70^{\text {defg }}$ \\
Sem Mo & $608,9^{\mathrm{a}}$ & $3,80^{\mathrm{ab}}$ & $62,70^{\mathrm{bcde}}$ & $10,20^{\mathrm{cde}}$ \\
Testemunha & $588,5^{\mathrm{ab}}$ & $3,70^{\mathrm{abc}}$ & $57,10^{\mathrm{bcde}}$ & $12,30^{\mathrm{bc}}$ \\
\hline \multicolumn{1}{c}{$\mathrm{CV}(\%)$} & 13,70 & 27,30 & 37,00 & 19,00 \\
\hline
\end{tabular}

*Médias seguidas de letras minúsculas iguais, na mesma coluna, não diferem entre si pelo teste de Tukey ao nível de $5 \%$. 


\section{CONCLUSÕES}

As plantas oriundas de mudas maduras e em condições de serem plantadas no local definitivo, tiveram o desenvolvimento afetado apenas pela omissão de $\mathrm{N}$ na solução nutritiva, exibindo diminuição na altura $\mathrm{e}$ no diâmetro do coleto, e menores teores foliares deste elemento. As omissões dos demais nutrientes afetaram levemente o desenvolvimento das plantas e a contribuíram com menores teores foliares apenas de Ca e Fe.

\section{AGRADECIMENTOS}

Os autores agradecem aos proprietários do Viveiro Mudas Nobres (Goiânia, GO) nas pessoas de Canrobert Tormim Borges e João Augusto da Silva, pela sessão da área experimental e subsídio de materiais utilizados na pesquisa.

\section{REFERÊNCIAS BIBLIOGRÁFICAS}

BATISTA, M. M. F.; VIÉGAS, I. de J. M.; FRAZÃO, D. A. C.; THOMAZ, M. A. A.; SILVA, R. de C. L. da. Efeito da omissão de macronutrientes no crescimento, nos sintomas de deficiências nutricionais e na composição mineral em gravioleiras (Annona muricata). Revista Brasileira de Fruticultura, Jaboticabal, v. 25, n. 2, p. 3।5-318, 2003.

CONCEIÇÃO, H. E. O. da; PINTO, J. E. B. P.; SANTIAGO, E. J. A. de; GONÇALVES, A. A. S. Crescimento e desenvolvimento de Derris urucu (Killip et Smith) na ausência de macronutrientes em solução nutritiva. Ciência e Agrotecnologia, Lavras, v. 26, p. 472-479, 2002.

DIAS, L. E.; ALVAREZ V., V. H.; BRIENZA Jr., S. Formação de mudas de Acacia mangium. I. Resposta à calcário e fósforo. In: CONGRESSO FLORESTAL BRASILEIRO - SOCIEDADE BRASILEIRA DE SILVICULTURA E SOCIEDADE BRASILEIRA DE ENG. FLORESTAIS, 6., 1990. Campos do Jordão. Anais... Campos do Jordão: 1990. p. 449-453.

FALESI, I. C.; BAENA, A. R. C. Mogno-africano (Khaya ivorensis A. Chev.) em sistema silvipastoril com leguminosa e revestimento natural do solo. Belém: Funtec, 1999. 52 p.

GONÇALVES, F. C.; NEVES, O. S. C.; CARVALHO, J. G. de. Deficiência nutricional em mudas de umbuzeiro decorrente da omissão de macronutrientes. Pesquisa Agropecuária Brasileira, Brasília, v. 4I, n. 6, p. I053-I057, 2006.

GROGAN, J.; BARReTO, P.; VerISSIMO, A. Mogno na Amazônia brasileira: ecologia e perspectiva de manejo. Belem: Imazon, 2002. 64 p.

JACOBSON, L. Maintenance of iron supply in nutrients solutions by a single addition of ferric potassium ethylene-diaminetetra-acetate. Jornal of Plant Physiology, Philadelphia, v. 26, n.2, p. 4I0-4II, 195I.
LEMMENS, R. H. M. J. 2008. Khaya ivorensis A.Chev. [Internet] registro de Protabase.Louppe, D., Oteng-Amoako, A.A.; Brink, M. (Editors). PROTA (Recursos Vegetais da África Tropical / Recursos de l'Afrique vegetales tropicale), Wageningen, Holanda.<Http://database.prota.org/search. htm >. Acessado em I4 de março de 2012.

MAFFEIS, A. R.; SILVEIRA, R. L. V. de A.; BRITO, J. O. Reflexos das deficiências de macronutrientes e boro no crescimento de plantas, produção e qualidade de óleo essencial em Eucalyptus citriodora. Scientia Forestalis, Piracicaba, n. 57, p. 87-98, 2000.

MALAVOLTA, E.; VITTI, G. C.; OLIVEIRA, S. A. de. Avaliação do estado nutricional das plantas: princípios e aplicações. 2. Ed., rev. e atual. Piracicaba: Potafós, 1997. 319 p.

PEREZ, P.L.; BACHA, C.J. C. Comercialização e comportamento dos preços da madeira serrada nos estados de São Paulo e Pará. Revista de Economia Agrícola, São Paulo, v. 54, n. 2, p. 103-I19, 2007.

SALVADOR, J. O.; MOREIRA, A.; MURAOKA, T. Sintomas de deficiências de micronutrientes e composição mineral de folhas em mudas de goiabeira. Pesquisa Agropecuária Brasileira., Brasília, v. 34, n. 9, p. 1655-1662, 1999.

SARCINELLI, T. S.; RIBEIRO JR., E. S.; DIAS, L. E.; LYNCH, L. de S. Sintomas de deficiência nutricional em mudas de Acacia holosericea em resposta à omissão de macronutrientes. Revista Árvore, Viçosa, v. 28, n. 2, p. |73-18|, 2004.

SARRUGE, J.R. Soluções nutritivas. Summa Phytopathologica, Botucatu, v. I, n.3, p.23I-33, 1975.

SEPIN - Secretaria do Planejamento e do Desenvolvimento do Estado de Goiás - SEPLAN. Superintendência de Pesquisa e Informação - SEPIN. 2003. Disponível em: <http:// www.seplan.go.gov.br/sepin/>. Acessado em: I5/09/II.

SILVEIRA, R. L. V. de; MOREIRA, A.; TAKASHI, E. N.; SGARBI, F; BRANCO, E. F. Sintomas de deficiência de macronutrientes e de boro em clones híbridos de Eucalyptus grandis com Eucalyptus urophylla. Cerne, Lavras, v. 8, n.2, p.107-II6, 2002.

VERZIGNASSI, J. R.; POLTRONIERI, L. S.; BENCHIMOL, R. L. Mancha-alvo em mogno-africano no Brasil. Summa Phytopathologica, Botucatu, v. 35, n. I, p. 70-7I, 2009.

VIÉGAS, I. de J. M.; THOMAZ, M. A. A.; SILVA, J. F. da; CONCEIÇÃO, H. E. O. da; NAIFF, A. P. M. Efeito da omissão de macronutrientes e boro no crescimento, nos sintomas de deficiências nutricionais e na composição mineral de plantas de camucamuzeiro. Revista Brasileira de Fruticultura, Jaboticabal, v. 26, n. 2, p. 315-319, 2004. 
VIEIRA, C. R.; WEBER, O. L. dos S.; SCARAMUZZA, J. F.; COSTA, A. C.; SOUZA, T. R. Descrição de sintomas visuais em função das deficiências de macronutrientes em mudas de cerejeira (Amburana acreana). Floresta, Curitiba, v. 4I, n. 4, p. $789-796,201$ I.
WALLAU, R. L. R. de; BORGES, A. R.; ALMEIDA, D. R. de; CAMARGOS, S. L. Sintomas de deficiências nutricionais em mudas de mogno em solução nutritiva. Cerne, Lavras, v. 14, n. 4, p. 304-310, 2008. 